Note

\title{
Effects of Sodium Chloride, Hydrogen Peroxide and Malachite Green on Fungal Infection in Rainbow Trout Eggs
}

\author{
NILUBOL KITANCHAROEN', ATSUSHI YAMAMOTO², \\ AND KISHIO HATAI ${ }^{1 *}$ \\ 'Division of Fish Diseases, Nippon Veterinary and Animal Science University, 1-7-1 \\ Kyonan-cho, Musashino, Tokyo 180-8602, and ${ }^{2}$ Oshino Trout Hatchery, Yamanashi Prefectural \\ Fisheries Technology Center, Oshino, Yamanashi 401-0511, Japan
}

Received 13 June 1997/Accepted 22 May 1998

\begin{abstract}
Two chemicals, sodium chloride and hydrogen peroxide were investigated for their efficacies as fungal control agents and compared with malachite green, fungal a control agent commonly used in hatcheries. No significant differences in results were seen between treatment with $1000 \mu \mathrm{g} / \mathrm{ml}$ hydrogen peroxide and that with $2 \mu \mathrm{g} / \mathrm{ml}$ malachite green in terms of the number of eggs infected and the hatching rate. When compared with the other two chemicals, sodium chloride at 25 ppt showed less effectiveness for fungal control.
\end{abstract}

Key words : Fungal control/Hydrogen peroxide/Malachite green/Rainbow trout egg/Sodium chloride.

In Japan, fungal infections in hatcheries are usually controlled with malachite green. Its antifungal activity is extremely effective, but the chemical is prohibited by the Food and Drug Administration (USA) for use as an antifungal agent in fish culturing because of its potential teratogenicity (Meyer and Jorgenson, 1983). Meinertz et al. (1995) suggested that undetectable residues of malachite green would remain in the fish grown from eggs exposed to the chemical until they reached market size. Thus the fish culturing industry in Japan needs an alternative antifungal agent which is effective and safe enough to replace malachite green.

Various treatment methods using sodium chloride or hydrogen peroxide as fungal control agents have been investigated, especially those using the former. Treatment with sea water at salinities ranging between 20.4 - 30.8 ppt for 2-3 h daily increased the survival rate and effectively controlled Saprolegnia diclina infection on the eggs of pink salmon, Oncorhynchus gorbuscha (Taylor and Bailey, 1979). Edgell et al. (1993) presented a treatment with 20 ppt

*Corresponding author. Tel and Fax: +81-422-31-6796. of a 26:1 mixture of sodium chloride and calcium chloride for $60 \mathrm{~min}$, three times a week, which was as effective as treatment with malachite green for fungal control on the eggs of chinook salmon, $O$. tshawytscha. Treatment by the continuous bath method with sea salt at a salinity of 0.5-2.5 ppt on the eggs of channel catfish, Ictalurus punctatus, in a recirculating-water system increased the hatching rate and reduced fungal infection (Phelps and Walser, 1993). Hydrogen peroxide was reported by Dawson et al. (1994) as effective in controlling fungal infection even on infected eggs by treatment with $1000 \mu \mathrm{g} / \mathrm{ml}$ for $60 \mathrm{~min}$.

Preliminary studies have indicated that sodium chloride and hydrogen peroxide are effective in controlling fungal infection on fish and fish eggs (Kitancharoen et al., 1997a, 1997b). Our objective was to determine the effectiveness of treatment with these two chemicals, both in controlling fungal infection and increasing the hatching rate in rainbow trout eggs, in comparison with that of treatment with malachite green.

The experiment was performed at Oshino Trout Hatchery, Yamanashi, Japan. The water source for this hatchery was well water with a temperature of 12 
TABLE 1. Fungal infection and hatching rates of rainbow trout eggs treated with sodium chloride, hydrogen peroxide and malachite green for $60 \mathrm{~min}$, twice a week.

\begin{tabular}{lcc}
\hline \multicolumn{1}{c}{ Chemical } & $\begin{array}{c}\text { Number of eggs colonized (\%) } \\
\text { (mean } \pm \text { S.D.) }\end{array}$ & $\begin{array}{c}\text { Hatching rate (\%) } \\
\text { (mean } \pm \text { S.D.) }\end{array}$ \\
\hline Control & $91.8 \pm 8.2$ & $1.5 \pm 1.5$ \\
Sodium chloride, $25 \mathrm{ppt}$ & $53.6 \pm 3.9$ & $38.9 \pm 3.8$ \\
Hydrogen peroxide, $1000 \mu \mathrm{g} / \mathrm{ml}$ & $27.6 \pm 8.1$ & $58.8 \pm 6.3$ \\
Malachite green, $2 \mu \mathrm{g} / \mathrm{ml}$ & $25.3 \pm 6.6$ & $62.1 \pm 5.8$ \\
\hline
\end{tabular}

$-13^{\circ} \mathrm{C}$ throughout the year. Under this condition, eggs could not be incubated without administration of fungal control. Therefore, malachite green has been routinely applied twice a week at a concentration of 2-3 $\mu \mathrm{g} / \mathrm{ml}$ for $60 \mathrm{~min}$.

Rainbow trout eggs were pooled from four 2-yr-old females and inseminated. About $1 \mathrm{~h}$ after insemination, the eggs were randomly separated into groups of 1000 eggs and held in meshed plastic baskets. Treatments were performed twice a week, in $10 l$ water with aeration in $20-l$ tanks. The antifungal agents used were $25 \mathrm{ppt}$ of sodium chloride, $1000 \mu \mathrm{g} / \mathrm{ml}$ of hydrogen peroxide and $2 \mu \mathrm{g} / \mathrm{ml}$ of malachite green, and each was used with a 60 - min exposure time. The concentrations of sodium chloride and hydrogen peroxide used in the present study were effective for fungal control without affecting the survival rate of rainbow trout eggs (Kitancharoen et al., 1997a, 1997b). After treatment, all groups were incubated in a 50-l plastic container supplied with running water flowing at a rate of approximately $1.8 \mathrm{l} / \mathrm{s}$. Fungal infection was allowed to occur naturally by exposure to fungal zoospores in the water supply. A control group, without treatment, was also provided. The eggs were observed for fungal infection and hatching rate 35 days after incubation. The experiment was undertaken for each group in triplicate.

As shown in Table 1, serious fungal infection, affecting $91.8 \pm 8.2 \%$ of the eggs, was observed in the control group, which resulted in a low hatching rate of $1.5 \pm 1.5 \%$. However, the degrees of infection and hatching rates varied in the experimental groups. No significant differences were observed in terms of fungal infection and hatching rate $(p<0.05)$ between the groups treated with malachite green and hydrogen peroxide. The group treated with sodium chloride showed a higher degree of infection and a lower hatching rate when compared with the groups treated with malachite green and hydrogen peroxide. The fungal infection rates and hatching rates of the groups treated with three chemicals, however, were significantly different when compared with those of the control group $(p<0.05)$. Furthermore, malachite green seemed to provide better fungal control than the other two chemicals as seen by unaided visual inspection, with less fungal adhesion between adjacent eggs in the group treated with malachite green.

The present study showed that hydrogen peroxide can be used effectively in place of malachite green as an antifungal agent, since the two chemicals are equally effective for fungal control. Sodium chloride proved less effective for fungal control when compared with the two chemicals, although the treatment with sodium chloride did inhibit fungal infection to some extent.

In a practical sense, a treatment with hydrogen peroxide accompanied by routine screening for dead eggs will increase the potential of the chemical to control fungal infection and increase the hatching rate.

\section{REFERENCES}

Dawson, V. K., Rach, J. J., and Schreier, T. M. (1994) Hydrogen peroxide as a fungicide for fish culture. Bull. Aquacul. Assoc. Canada, 2, 54-56.

Edgell, P., Lawseth, D., McLean, W. E., and Britton, E. W. (1993) The use of salt solutions to control fungus (Saprolegnia) infestations on salmon eggs. Prog. Fish-Cult., 55, 48-52.

Kitancharoen, N., Ono, A., Yamamoto, A., and Hatai, K. (1997a) The fungistatic activity of $\mathrm{NaCl}$ and its effect on the hatching rate of rainbow trout eggs. Fish Pathol., 32, 159-162.

Kitancharoen, N., Yamamoto, A., and Hatai, K. (1997b) Fungicidal activity of hydrogen peroxide on incubating of rainbow trout eggs. Mycoscience, 38, 375-378.

Meinertz, J. R., Stehley, G. R., Gingerich, W. H., and Allen, J. L. (1995) Residues of $\left[{ }^{14} \mathrm{C}\right]$-malachite green in eggs and fry of rainbow trout, Oncorhynchus mykiss (Walbaum), after treatment of eggs. J. Fish Dis., 18, 239-247. 
Meyer, F. P., and Jorgenson, T. A. (1983) Teratological and other effects of malachite green on the development of rainbow trout and rabbits. Trans. Amer. Fish. Soc., 112, 818-824.

Phelps, R. P., and Walser, C. A. (1993) Effect of sea salt on the hatching of channel catfish. J. Aqua.
Anim. Health, 5, 205-207.

Taylor, S. G., and Bailey, J. E. (1979) Saprolegnia: Control of fungus on incubating eggs of pink salmon by treatment with seawater. Prog. Fish-Cult., 41, 181-183. 